\section{TV commercial will unveil new brush to nation}

Oral-B, who pioneered both the electric toothbrush and connected brushing, has unveiled a new television commercial to introduce a whole new generation of brushing technology: Oral-B's new iO. The most advanced toothbrush on the market represents a new era of brushing technology, design and experience that delivers a professional clean feeling every single day.

Oral-B’s iO transforms brushing from something very functional, into a high-tech focus of beauty and desire, representing a completely new approach to how Oral-B advertises its products. This is something that has been replicated across the wider Oral-B product range, with the new brand Vis-ID using a deeper, more luxurious, colour palette and a series of revamped iconic assets that have been updated in line with the brand's renewed emphasis on advanced technology.

Oral-B's product performance is appreciated every day by over 17 million British consumers that use its toothbrushes. With the launch of the new TV commercial, Oral-B want to communicate what makes Oral-B electric toothbrushes so unique: the WOW feeling of a professional clean.

The TV ad campaign, created by PG ONE New York and PG ONE London, first aired on ITV and Channel 4 on the evening of 31 August. https://streamable.com/fq53aq

\section{For every indication}

Every case is different, which is why you need an imaging solution that is just as adaptable as you are.

The CS 9600 CBCT system from

Carestream Dental is the ideal choice for practitioners who want to be prepared for every scenario.

A state-of-the-art 5-in-1 imaging solution, this system combines $2 \mathrm{D}$ imaging capabilities with 3D CBCT, facial scanning and 3D model scanning to ensure that all of your current and future imaging needs are met.

Furthermore, the system is also upgradable to cephalometric imaging, ensuring that you really have all bases covered no matter how complex the case.

For more information, contact

Carestream Dental on 08001699692 or

visit www.carestreamdental.co.uk.

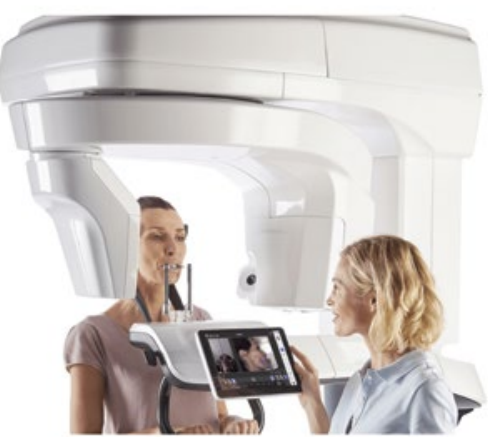

\section{No better time to join}

To learn how to deliver orthodonticrestorative dentistry, and receive a host of other benefits, join IAS Academy.

For a monthly fee, you will receive:

- A $20 \%$ discount on IAS training and events

- Discounts on partner products

- FREE access to webinars

- Continuous case mentoring on IAS appliances, via a purpose-designed platform
- Help with marketing and promotion

- And more.

Whether you are starting out or at an advanced stage of your career, the Academy will have something to offer you.

To be part of this inspiring global community, contact the IAS Academy today.

For more information on IAS Academy membership and upcoming training courses, visit www.iasortho.com or call 01932336470 (press 1).

\title{
Next generation milling
}

Clark Dental is proud to offer you cuttingedge dental technology that includes the next generation CEREC milling system from Dentsply Sirona.

Primemill enables you to manufacture a wide range of restorations with greater speed, precision and ease than ever before. Featuring an intuitive touchscreen interface with step-by-step user guidance, Primemill offers a full spectrum of

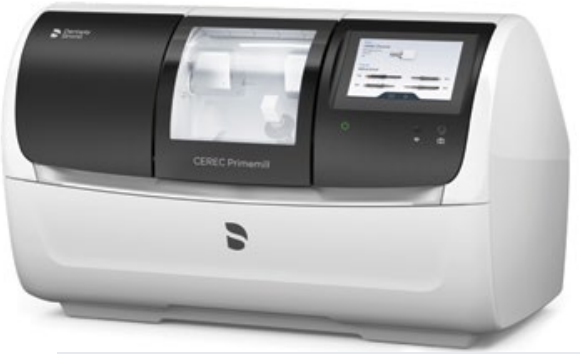

best-in-class machining options. This includes dry and wet milling of zirconia, or wet grinding of glass and hybrid ceramics.

With its highly accurate $0.5 \mathrm{~mm}$ milling tool, Primemill's Extra Fine mode achieves highly precise restoration margins and surface details, whilst Super Fast mode enables you to mill restorations in approximately five minutes, cutting processing times by over half.

Combine Primemill and the Primescan intraoral scanner with the latest CEREC software to ensure a complete workflow for designing and producing beautiful chairside restorations. Contact Clark Dental for a demonstration.

For more information call Clark Dental on 01268733 146, email info@clarkdental. co.uk or visit www.clarkdental.co.uk.

\section{Strong, stunning restorations}

\section{BRILLIANT COMPONEER is a veneering} system comprised of prefabricated shells, for strong and stunning restorations delivered chairside, in a single visit. Based on the same sub-micron filler technology as BRILLIANT EverGlow, BRILLIANT COMPONEER offers polishability, long-lasting gloss retention and mechanical strength.

With only minimally invasive preparation required, it is an ethical treatment. Patients will get a natural, functional result that lets them smile with confidence again.

COLTENE's tools and materials are developed to meet the needs of dentists and specialists who want to upgrade their dentistry.

Contact COLTENE to discover BRILLIANT COMPONEER. To find out more visitwww.coltene.com, email info.uk@ coltene.com or call 01444235486. 